\title{
Determine the Natural Radioactivity of the Sediment Wetlands in the Sea of Najaf, Iraq
}

\author{
Tahani M. Kadhim ${ }^{1}$, Heiyam N. Majeed ${ }^{2}$ \\ ${ }^{1,2}$ Kufa University, Education College of Girls, Department of Physics, Najaf, Iraq
}

\begin{abstract}
The natural radiation of seven sediment samples in the An Najaf Sea which collected randomly have been studied. they were measured using $3 " \times 3 " \mathrm{Na}(\mathrm{Tl})$ detection. The mean values concentrations of ${ }^{238} \mathrm{U},{ }^{232} \mathrm{Th}$ and ${ }^{40} \mathrm{~K}$ was $(8.621 \pm 0.352,0.353 \pm 0.017$ and $446.535 \pm 4.833) \mathrm{Bq} \mathrm{kg}-1$ respectively. Specific activity for all soil sample were in the worldwide average. The average values of the Radium equivalent activity and annual effective dose were $(43.509 \pm 0.750 \mathrm{~Bq} / \mathrm{kg}$ and $22.822 \pm 0.375 \mu \mathrm{Sv} / \mathrm{y})$ less than the world average. The heist external and internal hazard and gamma activity concentration index were $(0.09748,0.113636$ and 0.298963$)$ lower than unity.
\end{abstract}

Keywords: Gamma ray spectrometry, $\mathrm{Na}(\mathrm{Tl})$ detector, $\mathrm{Ra}_{\mathrm{eq}}$ activities and annual effective dose.

\section{Introduction}

An Najaf Sea, which is a geological phenomenon prominent in the Middle Euphrates region and the Sea of Najaf is located in the west end of the holy city in Najaf.

An Najaf Sea area is $750 \mathrm{Km}^{2}$. The high of the lowest point is 11 mabove sea surface and from a geological side; the floor was covered with modern sediment which thickness was up $38 \mathrm{~m}$.

The concentration of radioactive isotopes in soil were a path for radioactivity to humans and is an indicator of radioactive accumulation in the environment ]2].

Natural sources of radiation are cosmic radiation and terrestrial radiation arising from the decay of naturally occurring radioactive substance, the half life of a radionuclide found in geological strata approximates the estimated age of the earth, then the radionuclide is primordial it was presumably present from the time of the earth's beginning. Inventories of primordial radionuclide $s$ are essential parts of the natural background level of radioactivity in the environment the concentrations of the natural radio nuclides ${ }^{238} \mathrm{U},{ }^{232} \mathrm{Th}$, their daughter products and ${ }^{40} \mathrm{~K}$, present in the soil and rocks which in turn depend upon the local geology of each region in the world are causes of variation of doses. Some areas are high natural background areas because in these areas levels of uranium and its decay products in rock and soil, high background radiation areas are due to local geology, location altitude and geochemical effects that cause enhanced levels of terrestrial radiation[3-9].

\section{Experimental Procedures}

In this study, The natural radiation of seven sediment samples in the An Najaf Sea which collected randomly have been studied.

After collection the samples are crushed into fine powder by grinder the sample is obtained using scientific sieve .before measurement samples are dried in an oven at a temperature of $60 \mathrm{C}^{\circ}$ for $72 \mathrm{~h}$, each sample is packed and sealed in an airtight PVC container and kept for about (6) weeks period to allow radioactive equilibrium among the daughter products of radon $\left({ }^{222} \mathrm{Rn}\right)$, thoron $\left({ }^{220} \mathrm{Rn}\right)$ and their short lived decay products. An average $0.9 \mathrm{~kg}$ of soil is used per sample.

They were measured using Gamma spectrometer with scintillation detector $3 " \times 3 "$ inch $\mathrm{NaI}(\mathrm{Tl})$ from SPECTRUM TECHNIQUES, INC.USA the sample is placed face to face over the detector for $18000 \mathrm{sec}$, background contribution are subtracted from the peak area for the measured sample, because of the poor resolution of $\mathrm{NaI}(\mathrm{Tl})$ detector at low gamma energies which haven't well separated photo peak, thus the measuring of the activity concentrations is possible at high energies as that obtained in our results from gamma ray emitted by the progenies of ${ }^{238} \mathrm{U}$ (the gamma line $1765 \mathrm{keV}$ for ${ }^{214} \mathrm{Bi}$ ) and ${ }^{232} \mathrm{Th}$ (the gamma line $2614 \mathrm{keV}$ for ${ }^{208} \mathrm{Tl}$ ) which are in secular equilibrium with them while ${ }^{40} \mathrm{~K}$ was estimated directly by its gamma line of $1460 \mathrm{keV}[10,11]$ the fig.(1) determine Location of sample in the Sea of Najaf By using GPS while the fig.2 Illustrates the study areas. 


\section{International Journal of Science and Research (IJSR) \\ ISSN (Online): 2319-7064}

Index Copernicus Value (2013): 6.14 | Impact Factor (2014): 5.611

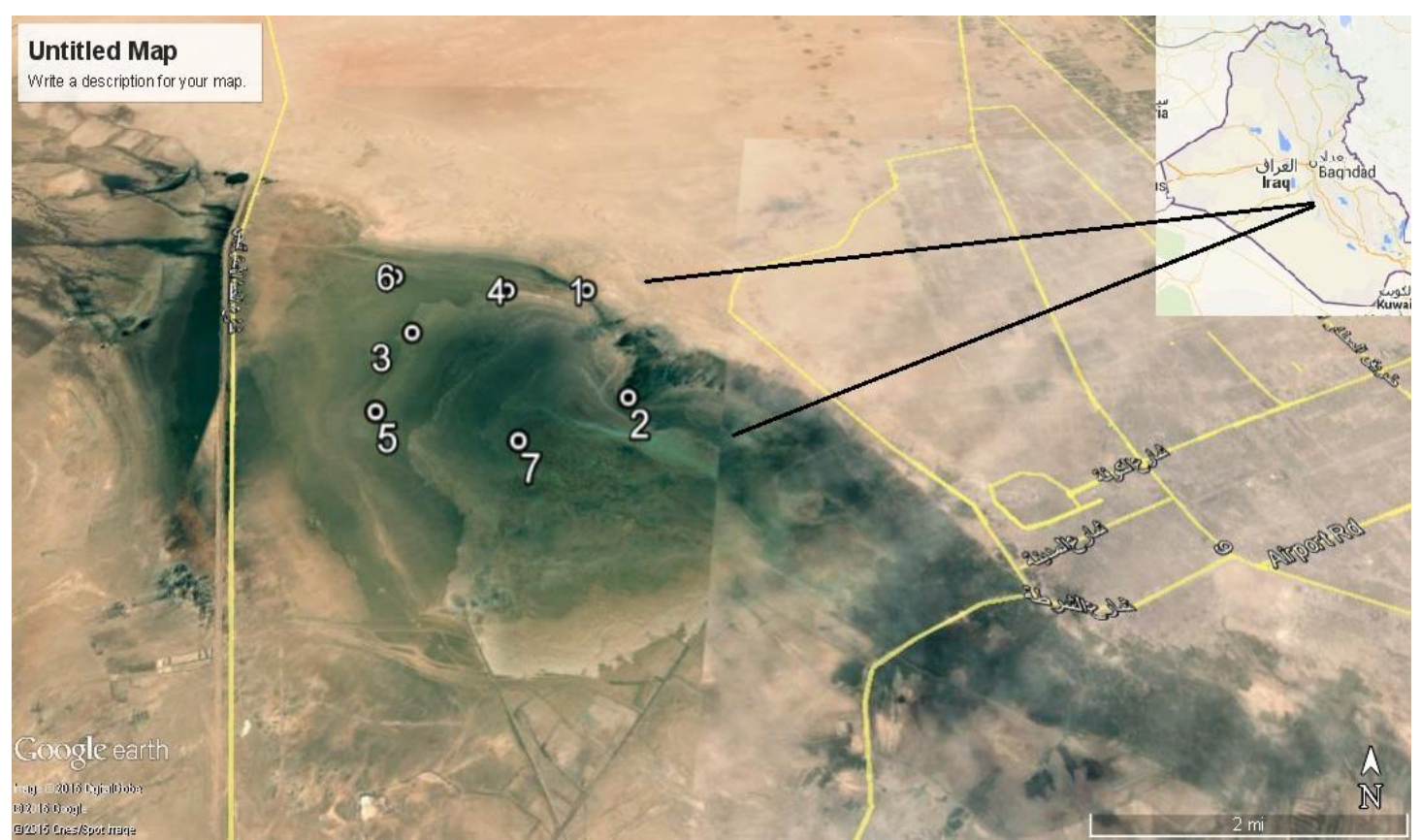

Figure 1: determine Location of sample in the Sea of NajafBy using GPS

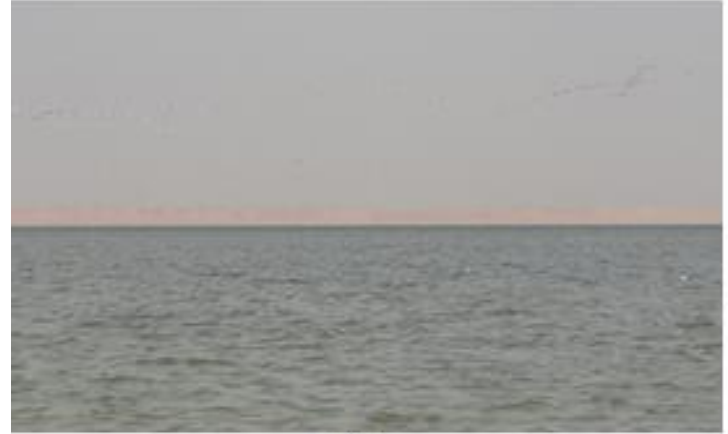

(a)

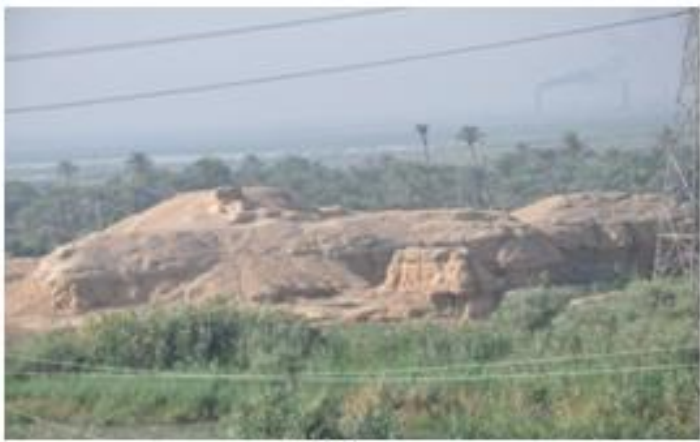

(b)

Figure 2:Illustrates the study areas of collect samples

The specific activity of each radionuclide is calculated using the following equation

$$
A=\frac{N_{n e t}}{\varepsilon \cdot I_{\gamma} \cdot m \cdot t} \pm \frac{\sqrt{N_{n e t}}}{\varepsilon \cdot I_{\gamma} \cdot m \cdot t}\left[B q \cdot \mathrm{kg}^{-1}\right]
$$

Where $N_{n e t}$ is the net count (area under the specified energy peak after back ground subtraction ) in (c/s), $\sqrt{N_{n e t}}$ is the random error in (c/s), $\varepsilon_{\text {is the efficiency of }}$ the detector, I $\gamma$ is the transition probability of the emitted gamma ray, $t$ is the time (in sec)for spectrum collected and $\mathrm{m}$ is the sample weight (in $\mathrm{kg}$ ).

Radium equivalent activity $\left(\mathrm{Ra}_{\mathrm{eq}}\right)$

Distribution of ${ }^{238} \mathrm{U},{ }^{232} \mathrm{Th}$ and ${ }^{40} \mathrm{~K}$ in environment is not uniform, so that with respect to exposure to radiation, the radioactivity has been defined in terms of radium equivalent activity (Raeq) in Bq.kg-1 [12-14].

$$
R a_{e q}=A_{U}+1.43 A_{T h}+0.077 A_{K} \ldots .
$$

Where $\mathrm{A}_{\mathrm{U}}, \mathrm{A}_{\mathrm{Th}}$ and $\mathrm{A}_{\mathrm{K}}$ are specific activity concentration in Bq.kg-1 of ${ }^{238} \mathrm{U}^{232} \mathrm{Th}$ and ${ }^{40} \mathrm{~K}$, respectively. The index is useful to compare the specific activity of materials containing different concentrations of ${ }^{238} \mathrm{U}^{232} \mathrm{Th}$ and ${ }^{40} \mathrm{~K}$.

\section{Gamma Dose Rate (D)}

The total dose rate $\mathrm{D}$ in the air (outdoors) due to uniform distribution of all the ${ }^{226} \mathrm{Ra},{ }^{232} \mathrm{Th}$ and ${ }^{40} \mathrm{~K}$ in the beach soil 1 $\mathrm{m}$ above the ground surface was estimated by [12-14]:

$$
D=0.427 A_{U}+0.662 A_{T h}+0.043 A_{K} \ldots . \text { (3) }
$$

Where $D$ is the dose rate in $\left(n G y \cdot h^{-1}\right)$ and $A_{U}, A_{T h}$ and $A_{K}$ are the concentrations of uranium, thorium and potassium, respectively.

\section{Annual Effective Dose Equivalent (AEDE)}

In order to estimate the annual effective dose rate in air the conversion coefficient from absorbed dose in air to effective dose received by an adult had to be taken into consideration .This value is published in UNSCEAR (2000)[5] of( 0.7 $\mathrm{Sv} / \mathrm{Gy})$.The outdoor occupancy factor which is about $(0.2)$.

The annual effective dose equivalent was given by the following equation[12-16] :

$\operatorname{AEDE}(\mu \mathrm{Sv} / \mathrm{y})=\mathrm{D}(\mathrm{nGy} / \mathrm{h}) \times 8760(\mathrm{~h} / \mathrm{y}) \times 0.2 \times 0.7(\mathrm{~Sv} / \mathrm{Gy}) \times 10^{-3}$

Representative level index (I $\gamma \mathrm{r})$

In order to examine whether the sample meets limits of dose criteria, Another radiation hazard index, representative level index I $\gamma \mathrm{r}$, used to estimate the level of $\gamma$-radiation hazard 


\section{International Journal of Science and Research (IJSR) \\ ISSN (Online): 2319-7064 \\ Index Copernicus Value (2013): 6.14 | Impact Factor (2014): 5.611}

associated with the radionuclides in specific investigated samples, is defind as the following equation [12-15]:

$$
I_{\gamma r}=A_{U} / 300+A_{T h} / 200+A_{K} / 3000
$$

The index I $\gamma \mathrm{r}$ was correlated with the annual dose due to the excess external gamma radiation caused by superficial material. Values of index I $\leq 1$ correspond to $0.3 \mathrm{mSv} / \mathrm{y}$, while $\mathrm{I} \leq 3$ correspond to $1 \mathrm{mSv} / \mathrm{y}$. Thus, the activity concentration index should be used only as a screening tool for identifying materials which might be of concern to be used as covering material. According to this dose criterion, materials with $\mathrm{I} \leq 3$ should be avoided[15].

External hazard index $\left(\mathrm{H}_{\mathrm{ex}}\right)$

The external hazard index $\left(\mathrm{H}_{\mathrm{ex}}\right)$ was given by the following equation[12-15]

$H_{e x}=\frac{A_{R a}}{370}+\frac{A_{T h}}{259}+\frac{A_{K}}{4810} \ldots \ldots$ (6)

Internal hazard index $\left(\mathrm{H}_{\text {in }}\right)$

The internal exposure to ${ }^{222} \mathrm{Rn}$ and its radioactive progeny is controlled by the internal hazard index $\left(\mathrm{H}_{\mathrm{in}}\right)$ is given by $[13,14]$

$$
H_{\text {in }}=\frac{A_{R a}}{185}+\frac{A_{T h}}{259}+\frac{A_{K}}{4810}
$$

For the safe use of a material in the construction of dwellings, index $\left(\mathrm{H}_{\mathrm{in}}\right)$ should be less than unity and the maximum value of $\left(\mathrm{H}_{\mathrm{in}}\right)$ to be less than unity.

\section{Results and Discussions}

The specific activity values of $238 \mathrm{U}, 232 \mathrm{Th}$ and $40 \mathrm{~K}$ radionuclide $\mathrm{s}$ for 7 soil sample are tabulated in table (1)\& fig. 3-5. They have been found to lie in the range of $(14.921 \pm 0.475 ; \mathrm{R} 4$ to $4.943 \pm 0.273 ; \mathrm{R} 3) \mathrm{Bq} / \mathrm{kg}$ with an average of $8.621 \pm 0.352 \mathrm{~Bq} / \mathrm{kg}$, from $(0.831 \pm 0.031 ; \mathrm{R} 5$ to $0.078 \pm 0.009 ; \mathrm{R} 4) \mathrm{Bq} / \mathrm{kg}$ with an average $0.353 \pm 0.017 \mathrm{~Bq} / \mathrm{kg}$ and $(619.649 \pm 5.809 ; \mathrm{R} 7$ to $140.477 \pm 2.766 ; \mathrm{R} 1) \mathrm{Bq} / \mathrm{kg}$ with an average $535 \pm 4.833 \mathrm{~Bq} / \mathrm{kg}$ for $238 \mathrm{U}, 232 \mathrm{Th}$ and $40 \mathrm{~K}$ respectively. The result shows that all values of $238 \mathrm{U}, 232 \mathrm{Th}$ and $40 \mathrm{~K}$ specific activity for all soil sample are in the worldwide average $(35 \mathrm{~Bq} / \mathrm{kg}$ for $238 \mathrm{U}, 30 \mathrm{~Bq} / \mathrm{kg}$ for $232 \mathrm{Th}$ and $400 \mathrm{~Bq} / \mathrm{kg}$ for $40 \mathrm{~K})$. [17,18[ .

Ra eq values vary from $(57.403 \pm 0.843 ; \mathrm{R} 7$ to $24.272 \pm 0.674$; $\mathrm{R} 1) \mathrm{Bq} / \mathrm{kg}$ with average value of $(43.509 \pm 0.750) \mathrm{Bq} / \mathrm{kg}$.It can see the $\mathrm{Ra}$ eq values for all samples are lower than the recommended value $370 \mathrm{~Bq} / \mathrm{kg}[17,18]$.

Gamma Dose Rate (D),Annual Effective Dose Equivalent (AEDE), Rate (D) range from $(30.311 \pm 0.424$; 7 to $12.071 \pm$ $0.328 ; \mathrm{R} 1) \mathrm{nGy} / \mathrm{h}$ with average $22.822 \pm 0.375 \mathrm{nGy} / \mathrm{h} .446$.

Table 1: Activity Concentration in (Bqkg-1) in Different Active Soil Samples

\begin{tabular}{|c|c|c|c|c|c|}
\hline \multirow{2}{*}{$\begin{array}{c}\text { Gamma } \\
\text { DoseRate } \\
\text { (nGy.h } \mathbf{~}^{\mathbf{1}} \mathbf{)}\end{array}$} & \multirow{2}{*}{$\begin{array}{c}\text { Radium } \\
\text { equivalent } \\
\mathbf{( B q} / \mathbf{K g})\end{array}$} & ${ }^{232} \mathbf{T h}$ & ${ }^{238} \mathbf{U}$ & ${ }^{40} \mathbf{K}$ & \multirow{2}{*}{ Sample No. } \\
\cline { 3 - 6 } & & & & \\
\hline $12.071 \pm 0.328$ & $24.272 \pm 0.674$ & $0.078 \pm 0.009$ & $13.344 \pm 0.449$ & $140.477 \pm 2.766$ & R1 \\
\hline $20.167 \pm 0.345$ & $38.181 \pm 0.686$ & $0.554 \pm 0.025$ & $5.337 \pm 0.284$ & $416.258 \pm 4.761$ & R2 \\
\hline $16.081 \pm 0.308$ & $30.449 \pm 0.613$ & $0.101 \pm 0.010$ & $4.943 \pm 0.273$ & $329.379 \pm 4.235$ & R3 \\
\hline $28.892 \pm 0.448$ & $55.565 \pm 0.900$ & $0.078 \pm 0.009$ & $14.921 \pm 0.475$ & $526.396 \pm 5.354$ & R4 \\
\hline $27.169 \pm 0.386$ & $51.218 \pm 0.765$ & $0.831 \pm 0.031$ & $5.534 \pm 0.289$ & $577.870 \pm 5.610$ & R5 \\
\hline $25.065 \pm 0.386$ & $47.476 \pm 0.768$ & $0.712 \pm 0.029$ & $6.748 \pm 0.319$ & $515.720 \pm 5.300$ & R6 \\
\hline $30.311 \pm 0.424$ & $57.403 \pm 0.843$ & $0.117 \pm 0.011$ & $9.523 \pm 0.380$ & $619.649 \pm 5.809$ & R7 \\
\hline $22.822 \pm 0.375$ & $43.509 \pm 0.750$ & $0.353 \pm 0.017$ & $8.621 \pm 0.352$ & $446.535 \pm 4.833$ & Average \\
\hline $30.311 \pm 0.424$ & $57.403 \pm 0.843$ & $0.831 \pm 0.031$ & $14.921 \pm 0.475$ & $619.649 \pm 5.809$ & Max. \\
\hline $12.071 \pm 0.328$ & $24.272 \pm 0.674$ & $0.078 \pm 0.009$ & $4.943 \pm 0.273$ & $140.477 \pm 2.766$ & Min. \\
\hline
\end{tabular}

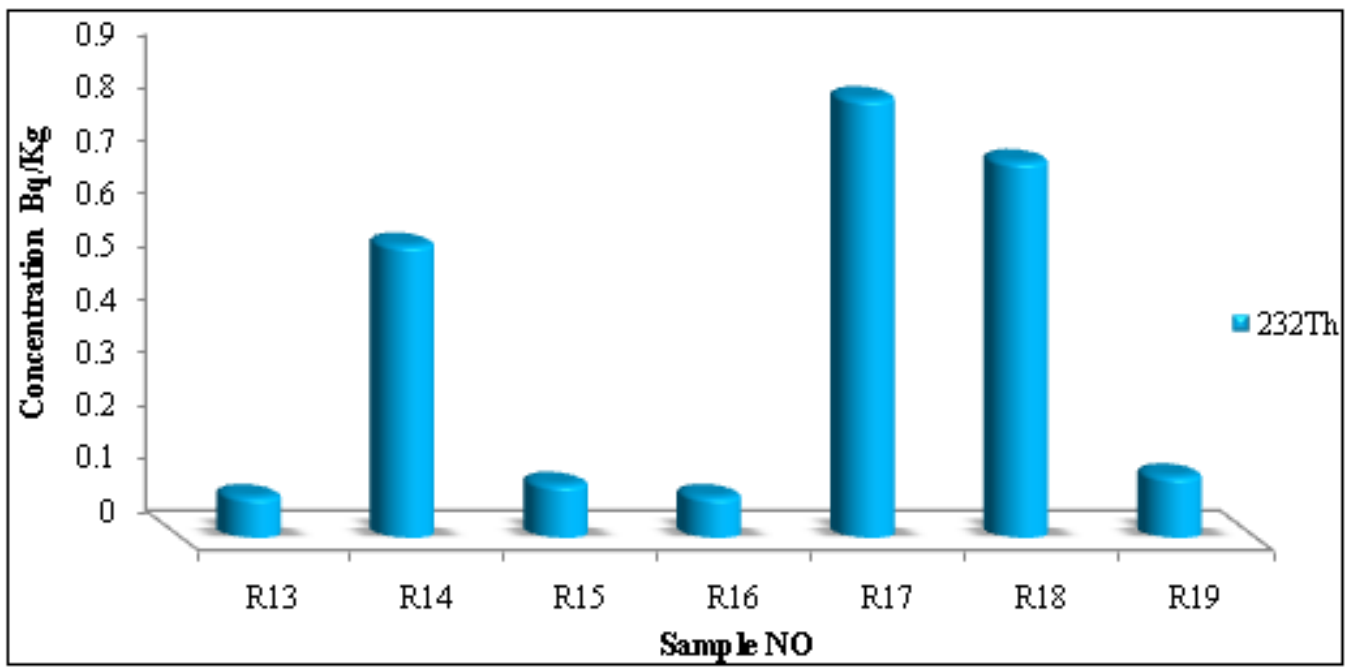

Figure3: Illustrates the concentrations of ${ }^{232} \mathrm{Th}$ in sediment samples taken from the Sea of Najaf 


\section{International Journal of Science and Research (IJSR) \\ ISSN (Online): 2319-7064}

Index Copernicus Value (2013): 6.14 | Impact Factor (2014): 5.611

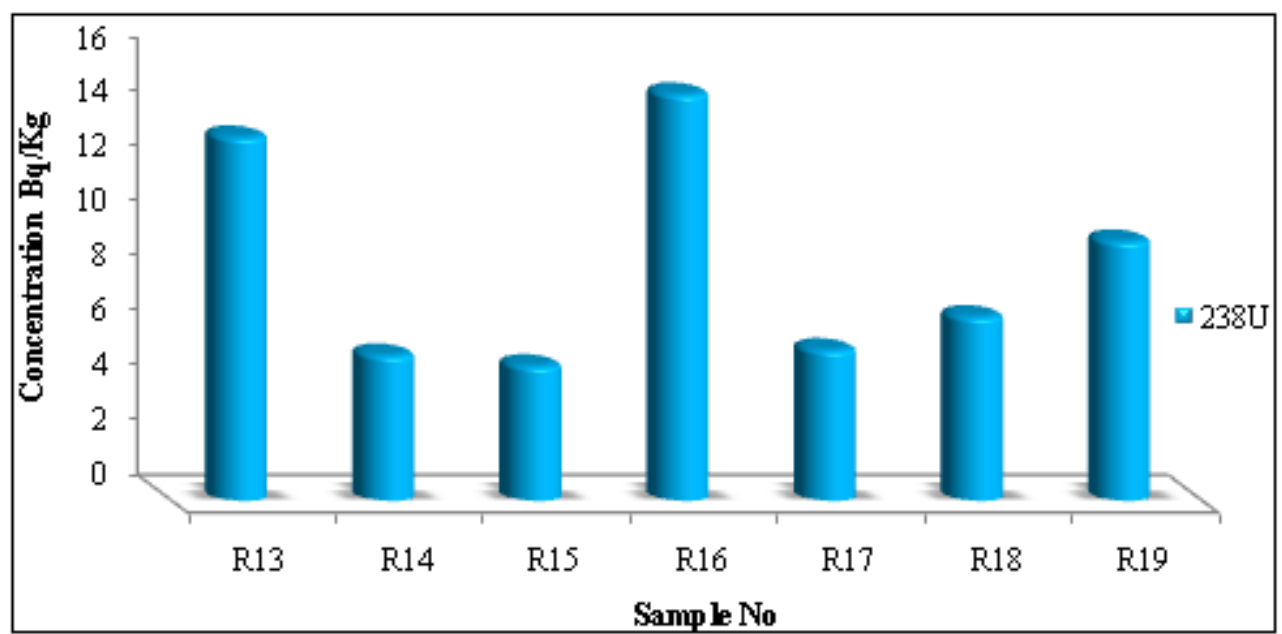

Figure4: Illustrates the concentrations of ${ }^{228} \mathrm{U}$ rates of sediment samples taken from the Sea of Najaf

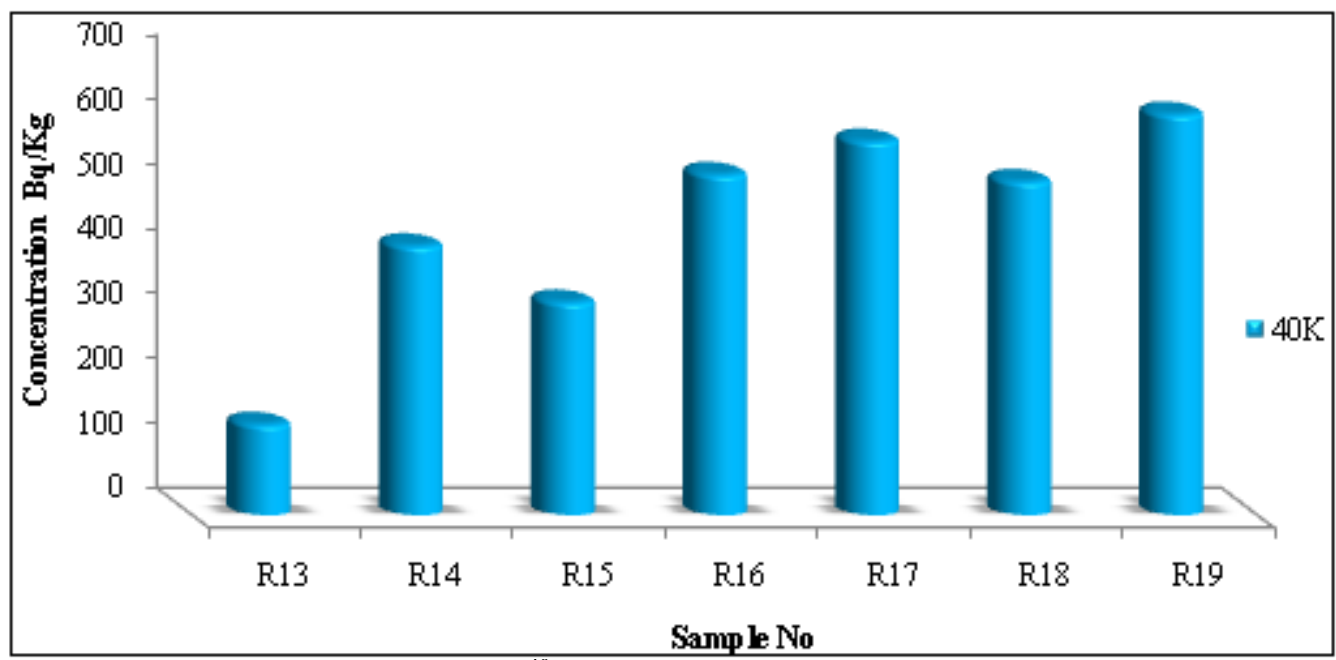

Figure5: Illustrates concentrations of ${ }^{40} \mathrm{~K}$ rates of sediment samples taken from the Sea of Najaf

Representative level index (I $\gamma \mathrm{r})$, External hazard index (Hex) and Internal hazard index (Hin) are calculated andthe Gamma Dose listed in table (2), the (AEDE) rang are from $(0.0371 \pm 00005 ; \mathrm{R} 7$ to $0.0148 \pm 0.0004 ; \mathrm{R} 1)(\mu \mathrm{Sv} / \mathrm{y})$ with average $0.0279 \pm 0.1408(\mu \mathrm{Sv} / \mathrm{y})$ all the soil samples have the annual effective dose less than the world average 460 $(\mu \mathrm{Sv} / \mathrm{y})$ [17,18], Representative level index (I $\gamma \mathrm{r})$ range from $(0.477756 ; \mathrm{R} 7$ to $0.183391 ; \mathrm{R} 1)$ with average
0.358697, External hazard index (Hex) range from $(0.155014 ; \mathrm{R} 7$ to $0.065571 ; \mathrm{R} 1)$ with average 0.117499 and Internal hazard index (Hin) range from $(0.190393$;R4 to $0.095586 ; \mathrm{R} 3)$ with average 0.1408 . External and internal hazard and gamma activity concentration were lower than unity according to the Radiation Protection 112 [17].

Table 2: Radium equivalent (Bq.kg-1), Dose rate (nGy/h), AEDE ( $\mu$ Sv/y), the internal and external hazard indexes representative level index for all samples

\begin{tabular}{|c|c|c|c|c|c|}
\hline \multirow{2}{*}{$\begin{array}{c}\text { Representative level } \\
\text { index }\left(\mathrm{I}_{\gamma}\right)\end{array}$} & \multicolumn{2}{|c|}{ Hazard Index } & \multicolumn{2}{c|}{ Effective dose rate $m S v \cdot y r^{-1}$} & \multirow{2}{*}{ S.No } \\
\cline { 2 - 6 } & $\begin{array}{c}\text { Internal } \\
\left(\mathrm{H}_{\mathrm{in}} \geq 1\right)\end{array}$ & $\begin{array}{c}\text { External } \\
\left(\mathrm{H}_{\mathrm{ex}} \geq 1\right)\end{array}$ & (Indoor) & & \\
\hline 0.183391 & 0.101636 & 0.065571 & $0.0592 \pm 0.0016$ & $0.0148 \pm 0.0004$ & $\mathrm{R} 1$ \\
\hline 0.318625 & 0.117527 & 0.103103 & $0.0989 \pm 0.0016$ & $0.0247 \pm 0.0004$ & $\mathrm{R} 2$ \\
\hline 0.253549 & 0.095586 & 0.082227 & $0.0788 \pm 0.0015$ & $0.0197 \pm 0.0003$ & $\mathrm{R} 3$ \\
\hline 0.451184 & 0.190393 & 0.150066 & $0.1417 \pm 0.0021$ & $0.0354 \pm 0.0005$ & $\mathrm{R} 4$ \\
\hline 0.43045 & 0.153261 & 0.138304 & $0.1332 \pm 0.0018$ & $0.0333 \pm 0.0004$ & $\mathrm{R} 5$ \\
\hline 0.39592 & 0.146443 & 0.128205 & $0.1229 \pm 0.0018$ & $0.0307 \pm 0.0004$ & $\mathrm{R} 6$ \\
\hline 0.477756 & 0.180752 & 0.155014 & $0.1486 \pm 0.0020$ & $0.0371 \pm 0.0005$ & $\mathrm{R} 7$ \\
\hline 0.358697 & 0.1408 & 0.117499 & $0.1119 \pm 0.3586$ & $0.0279 \pm 0.1408$ & Average \\
\hline 0.477756 & 0.190393 & 0.155014 & $0.1486 \pm 0.0020$ & $0.0371 \pm 0.0005$ & Max \\
\hline 0.183391 & 0.095586 & 0.065571 & $0.0592 \pm 0.0016$ & $0.0148 \pm 0.0004$ & Min. \\
\hline
\end{tabular}




\section{International Journal of Science and Research (IJSR) \\ ISSN (Online): 2319-7064}

Index Copernicus Value (2013): 6.14 | Impact Factor (2014): 5.611

\section{Conclusions}

The activity concentrations of ${ }^{238} \mathrm{U},{ }^{232} \mathrm{Th}$ and ${ }^{40} \mathrm{~K}$ for (7) Sediment sample from the Sea of Najaf was determined . The mean values activity concentrations of ${ }^{238} \mathrm{U},{ }^{232} \mathrm{Th}$ and ${ }^{40} \mathrm{~K}$ was $(8.621 \pm 0.352,0.353 \pm 0.017$ and $446.535 \pm 4.833)$ Bq kg-1 respectively.

The values of the Radium equivalent activity and annual effective dose was less than the world averageExcept ${ }^{40} \mathrm{~K}$.

External and internal hazard and gamma activity concentration (representative level index) indexes were lower than unity.

\section{References}

[1] A.Msitah, H.Zaini, S.Ahmad. O.Mohamat and W.AbdulKhalik. An assessment of absorbed dose and radiationhazard index from natural radioactivity, Journal of Analytical sciences, 12, PP.195-204, 2008.

[2] G. Choppin, R. Rydberg and J. Liljenzin "radiochemistry and nuclear chemistry " 2 nd edition of nuclear chemistry theory and applications, New York, Pergmon Press, (1995)

[3] L. Quindos, P. Fernandez, C. Rodenas, J. GomezArozamena and J. Arteche, "Conversion factors for external gamma dose derived from natural radionuclides in soils", Journal of Environmental Radioactivity, 71, 139- 145 (2004).

[4] H. Ibrahim, A. Hafez, N. Elanany, H. Motaweh and M. Naim; "Radiological Study on Soils, Foodstuff and Fertilizers in the Alexandria Region, Egypt", Turkish J. Eng. Env. Sci. 30, 1-9 (2006).

[5] United Nations Scientific Committee on the Effects of Atomic Radiation, Sources, Effects and Risks of Ionizing Radiation, New York, United Nations, 2000.

[6] K.M.Thabayneh and M.M Jazzar, " Natural Radioactivity Levels and Estimation of Radiation Exposure in Environmental Soil SamplesfromTulkarem Province - Palestine ", University of Hebron, Palestine, (2012).

[7] Herman C. and Thomas E.J., "Health Physics", $4^{\text {th }}$ Ed, McGraw- Hill Companies, Inc., 2009.

[8] Naturally Occurring Radioactive Material (NORM V) Proceedings of an international symposium Seville, Spain, 19-22 March 2007

[9] L. Colmenero Sujo, M. Montero Cabrera, L. Villalba, M. Renterı'a Villalobos, E. Torres Moye, M. Garc Leon, R. Garc -Tenorio, . Mireles Garcı, E. Herrera Peraza and D. Sanchez Aroche " Uranium-238 and thorium-232 series concentrations in soil, radon-222 indoor and drinking water concentrations and dose assessment in the city of Aldama, Chihuahua, Mexico', Journal of Environmental Radioactivity 77, 205219,(2004).

[10]IAEA, International atomic energy agency, Update of $\mathrm{x}$ ray and gamma ray decay data standards for detector calibration and other applications, Volume 1, Vienna, 2007.

[11]IAEA, International atomic energy agency, "Guidelines for radioelement mapping using gamma ray spectrometry data", Vienna, (2003).
[12]H .Al-Sulaiti, P .Regan, D .Bradley, M .Matthews, T. Santawamaitre and D .Malain, "Preliminary Determination of Natural Radioactivity Levels of the State of Qatar using High Resolution Gamma ray spectrometry",IX Radiation. Physics \& Protection Conference, 15-19 November Nasr City - Cairo, Egypt (2008) .

[13] S. Radenković,V.Alshikh,V. Andric, and S. Miljanic, J. Serb. Chem. Soc. $74: 461-470$, (2009).

[14]S .Harb, A.El-Kamel, A.Abd El-Mageed and R.Wafaa,Proceedings of the 3 rd Environmental Physics Conference, 19-23 Feb. Aswan, Egypt (2008).

[15]F.Al - Saleh and B .Al-Berzan, Journal of Nuclear and Radiation Physics 2,25-36, (2007).

[16] Organization for Economic Cooperation and Development, "Exposure to radiation from the natural radioactivity in building materials". Report by a group of experts of the OECD Nuclear Energy Agency, OECD, Paris, France (1979).

[17]European Commission. Radiation Protection 112" Radiological protection principles concerning the natural radioactivity of building materials", Brussels, European Commission, (1999).

[18] International Commission on Radiological Protection, ICRP publication 65, Annals of the ICRP 23(2). Pergamon Press, Oxford, (1993). 